\title{
Bibliometric analysis of worldwide scientific literature in mobile - health: 2006-2016
}

\author{
Waleed M. Sweileh ${ }^{1 *}$, Samah W. Al-Jabi ${ }^{2}$,Adham S. AbuTaha', Sa'ed H. Zyoud², Fathi M. A. Anayah \\ and Ansam F. Sawalha'
}

\begin{abstract}
Background: The advancement of mobile technology had positively influenced healthcare services. An emerging subfield of mobile technology is mobile health ( $\mathrm{m}$-Health) in which mobile applications are used for health purposes. The aim of this study was to analyze and assess literature published in the field of m-Health.

Methods: SciVerse Scopus was used to retrieve literature in m-Health. The study period was set from 2006 to 2016. ArcGIS 10.1 was used to present geographical distribution of publications while VOSviewer was used for data visualization. Growth of publications, citation analysis, and research productivity were presented using standard bibliometric indicators.

Results: During the study period, a total of 5465 documents were published, giving an average of 496.8 documents per year. The $h$-index of retrieved documents was 81 . Core keywords used in literature pertaining to $m$-Health included diabetes mellitus, adherence, and obesity among others. Relative growth rate and doubling time of retrieved literature were stable from 2009 to 2015 indicating exponential growth of literature in this field. A total of 4638 (84.9\%) documents were multi-authored with a mean collaboration index of 4.1 authors per article. The United States of America ranked first in productivity with 1926 (35.2\%) published documents. India ranked sixth with 183 (3.3\%) documents while China ranked seventh with 155(2.8\%) documents. VA Medical Center was the most prolific organization/institution while Journal of Medical Internet Research was the preferred journal for publications in the field of $\mathrm{m}$-Health. Top cited articles in the field of m-Health included the use of mobile technology in improving adherence in HIV patients, weight loss, and improving glycemic control in diabetic patients.

Conclusion: The size of literature in $\mathrm{m}$-Health showed a noticeable increase in the past decade. Given the large volume of citations received in this field, it is expected that applications of $\mathrm{m}$-Health will be seen into various health aspects and health services. Research in m-Health needs to be encouraged, particularly in the fight against AIDS, poor medication adherence, glycemic control in Africa and other low income world regions where technology can improve health services and decrease disease burden.
\end{abstract}

Keywords: Mobile Health, Bibliometric, VOSviewer

\section{Background}

Mobile health (mHealth or m-Health) was defined more than a decade ago as the use of mobile communication devices in health services or as an emerging application of mobile technologies for healthcare systems [1-3]. The world health organization (WHO) defined $\mathrm{m}$-Health as "medical and public health practice supported by mobile

\footnotetext{
* Correspondence: waleedsweileh@yahoo.com

${ }^{1}$ Department of Physiology, Pharmacology and Toxicology, College of Medicine and Health Sciences, An-Najah National University, Nablus, Palestine

Full list of author information is available at the end of the article
}

devices, such as mobile phones, patient monitoring devices, personal digital assistants (PDAs), and other wireless devices" [4]. Mobile health is a relatively recent field that emerged as a branch or component of health which involves the use of wireless technology or electronic processes in health services [5]. Many published reports indicated that $\mathrm{m}$-health had a positive impact on individual and national health services [6]. Mobile health had been applied in a wide range of health services including promoting medication adherence, prevention of behaviors associated with certain diseases, psychological support for 
Table 1 Types of retrieved documents (2006-2016)

\begin{tabular}{lll}
\hline Type of document & Frequency & $\%$ \\
& & $\mathrm{~N}=5465$ \\
\hline Article & 4194 & 76.7 \\
Review & 523 & 9.6 \\
Note & 199 & 3.6 \\
Letter & 198 & 3.6 \\
Article in Press & 116 & 2.1 \\
Editorial & 91 & 1.7 \\
Conference Paper & 78 & 1.4 \\
Short Survey & 66 & 1.2 \\
Total & 5465 & $100 \%$ \\
\hline
\end{tabular}

patients with chronic diseases, weight loss, smoking cessation and many others [7-18].

Bibliometrics and scientometrics are defined as mathematical/statistical methods used to assess the quality and quantity of published scientific literature and to study research trends, citation analysis, authorship, impact of publications, journal analysis, as well as national and international contribution in a particular field. Bibliometrics and scientometrics had been applied to many scientific fields including mobile technology and telecommunication [19-23]. However, up until this date, no bibliometric analysis of scientific literature in $\mathrm{m}$ Health had been carried out and published. Therefore, the aim of this study was to analyze published literature in $\mathrm{m}$-Health. In specific, growth of publications, country contribution, international collaboration, citation analysis, keyword occurrences, authorship analysis, most productive institutions, and most productive journals in the field of $\mathrm{m}$-Health were investigated.

\section{Methods \\ Bibliographic database}

In this study, data pertaining to $\mathrm{m}$-Health were retrieved from Scopus, a bibliographic database that covers nearly 22,000 titles in the scientific, technical, medical, and social sciences. The choice of Scopus was made based on the idea that it is the largest database when compared to Pubmed or Web of Science [24]. Furthermore, several analytical functions can be performed using Scopus (Additional file 1). One such function was "source type" which allowed us to refine retrieved literature based on type of data source whether the source was journal publications or books or book chapters or conference proceedings or trade publications. In this study, we limited our analysis to documents published in journals but not in books or conference proceedings (Additional file 1). Conference proceedings included abstracts which might have been published twice as a conference abstract and as a full journal article and therefore might create false positive results. Once the source type was limited to journal publications, the type of these publications can be explored using the function "document type" (Additional file 1). In document type, errata documents, corrections of an already published articles, were excluded from the analysis since they do not represent true publications. The conference papers that appeared under document type were different from those that appeared under source type. In document type, conference papers refer to papers presented in

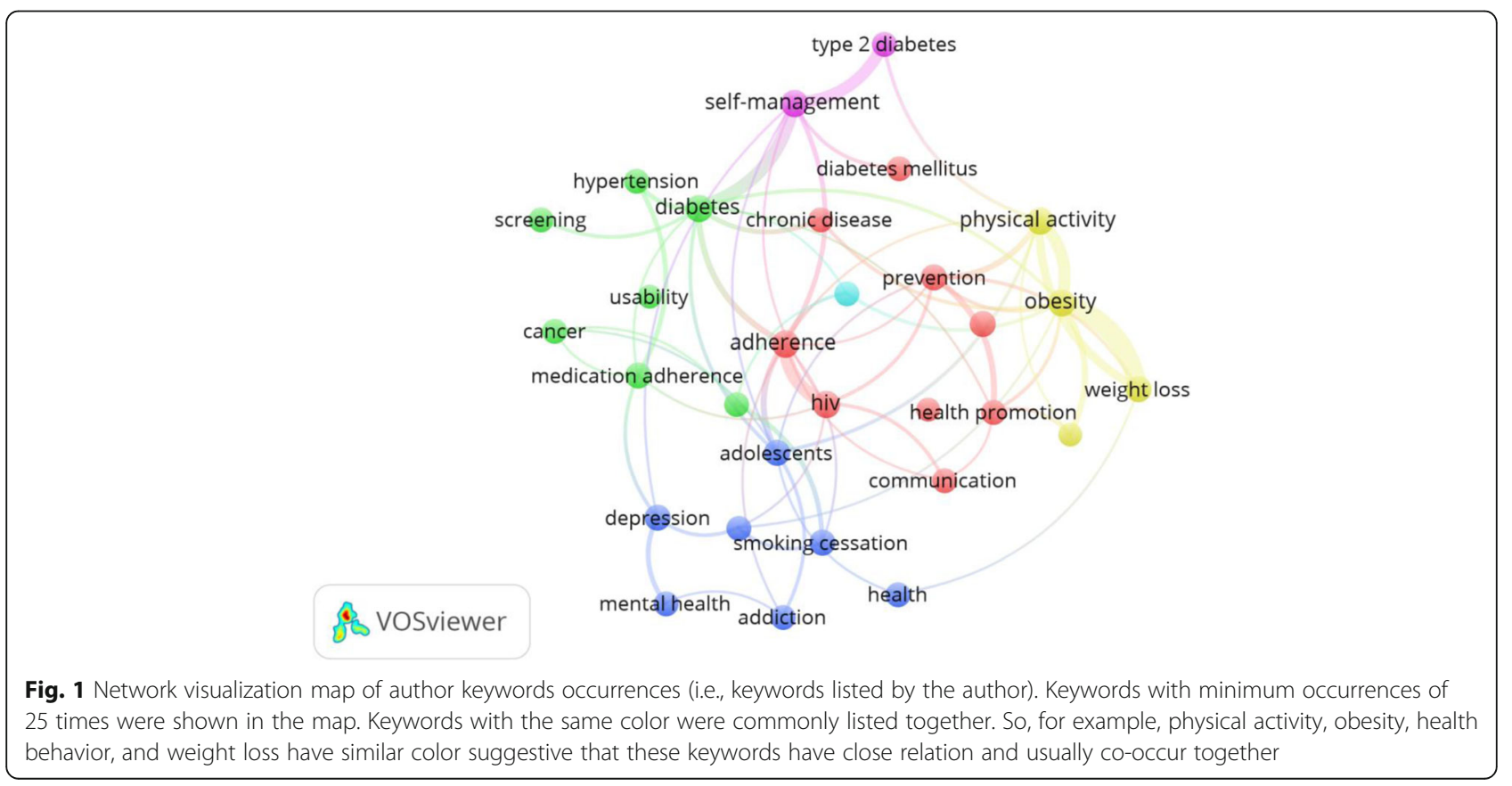


conferences and were published as full journal articles and therefore could not be published twice. This approach of limiting source data to journal publications will minimize false positive, particularly for those which originated from conference proceedings.

\section{Search strategy and validity}

Our search strategy was based on two approaches that were combined at a later step. The first approach included search for journal publications in which the term ("mobile health") appeared in the title or abstract or author keywords. However, since not all publications in mobile health could be retrieved this way, we had to use a second approach in which we searched for all possible documents that included in their titles words related to mobile technology such as smartphone or texting or cellular phone or mobile application plus a word in any field of health. In each approach, the time was set from 2006 to 2016 and source type was limited to journal publications. The number of documents retrieved using each approach was shown in Additional file 1. The first approach yielded a total of 2452 (Additional file 1) while the second approach yielded a total of 3263 (Additional file 1) and when combined, they yielded a total of 5465 journal publications. The overlap between the two approaches was 250 documents. One might ask why search for the term "mobile health" did not yield all potential documents and the answer for that was the tendency of some researchers to use terms such as smartphones or text message in addition to the disease or ailment being investigated instead of using the recently defined term "m-Health". Furthermore, some researchers might use broader terms such as telemedicine. Therefore, it was not surprising that the term "mobile health" did not retrieve all needed documents and the use of a second detailed approach was needed. The overall search strategy was shown in Additional file 1. In the second approach, the health related terms were obtained from several systematic reviews and review articles in $\mathrm{m}$-Health to ensure conclusiveness of the search strategy [25-33]. For validity of the search strategy, two co-authors manually reviewed 110 articles chosen as top 10 cited articles for each year in the study period. For all manually reviewed articles, no false positive results were obtained. Furthermore, the preferred journal names in which publications appeared indicated that the retrieved articles were within the correct scope.

\section{Data analysis}

Retrieved data were analyzed for document type, annual growth, citation analysis, authorship, country productivity, and for articles with the highest number of citations. Document types were presented as frequency and percentage.
Table 2 Annual number of publications and citation analysis per year (2006 - 2016)

\begin{tabular}{llllll}
\hline Year & Frequency & $\begin{array}{l}\% \\
N=5465\end{array}$ & TC & $\begin{array}{l}\text { Mean } \pm \text { SD } \\
\text { of citations }\end{array}$ & $\begin{array}{l}\text { Median } \\
\text { (Q1 }- \text { Q3) } \\
\text { of citations }\end{array}$ \\
\hline 2006 & 155 & 2.8 & 2438 & $15.7 \pm 33.8$ & $5(1-17)$ \\
2007 & 176 & 3.2 & 3248 & $18.5 \pm 31.5$ & $11(1-21.75)$ \\
2008 & 189 & 3.5 & 3646 & $19.3 \pm 32.6$ & $6(1-20.5)$ \\
2009 & 234 & 4.3 & 4955 & $21.2 \pm 42.7$ & $6(1-23)$ \\
2010 & 288 & 5.3 & 5994 & $20.8 \pm 45.6$ & $7(1-24.75)$ \\
2011 & 343 & 6.3 & 6886 & $16.6 \pm 39.7$ & $4(0-17)$ \\
2012 & 505 & 9.2 & 8332 & $20.1 \pm 26.7$ & $7(2-21)$ \\
2013 & 630 & 11.5 & 8581 & $13.6 \pm 23.4$ & $6(2-16)$ \\
2014 & 861 & 15.8 & 6179 & $7.2 \pm 11$ & $3(1-9)$ \\
2015 & 989 & 18.1 & 3749 & $3.8 \pm 6.7$ & $2(0-4.5)$ \\
2016 & 1095 & 20.0 & 929 & $0.8 \pm 1.8$ & $0(0-1)$ \\
\hline
\end{tabular}

TC Total citations, SD Standard deviation, Q1-Q3 Interquartile range

For annual growth, we presented data as number of retrieved documents in each year. Furthermore, the annual growth rate (AGR), defined as the percentage change in the number of publications over a period of 1 year was calculated based on the following equation: $A G R=[($ Ending Value - Beginning Value)/Beginning Value] *100.

The growth analysis was also presented as relative growth rate (RGR) which was defined as the increase in number of publications per unit of time. The RGR was calculated based on the following equation: $R G R$ $=\left[\log _{e} W_{2}-\log _{e} W_{1}\right] /(T 2-T 1)[19,34,35]$ where $\log _{\mathrm{e}} \mathrm{W}_{1}$ : $\log$ of initial number of articles; $\log _{\mathrm{e}} \mathrm{W}_{2}$ : $\log$ of final number of articles after a specific period of interval; and T2-T1: the unit difference between the initial time and the final time. The RGR can be presented in a different format called doubling time (DT), defined as the period

Table 3 Annual number of publications, AGR, RGRT, and DT (2006-2016)

\begin{tabular}{lllllll}
\hline Year & Frequency & AGR & $\begin{array}{l}\text { Cumulative total } \\
\text { publications }\end{array}$ & $\log _{e} W$ & RGR & DT \\
\hline 2006 & 155 & - & 155 & 5.0 & - & - \\
2007 & 176 & 13.5 & 331 & 5.8 & 0.8 & .9 \\
2008 & 189 & 7.4 & 520 & 6.3 & 0.5 & 1.4 \\
2009 & 234 & 23.8 & 754 & 6.6 & 0.3 & 2.3 \\
2010 & 288 & 23.1 & 1042 & 6.9 & 0.3 & 2.3 \\
2011 & 343 & 19.1 & 1385 & 7.2 & 0.3 & 2.3 \\
2012 & 505 & 47.2 & 1890 & 7.5 & 0.3 & 2.3 \\
2013 & 630 & 24.8 & 2520 & 7.8 & 0.3 & 2.3 \\
2014 & 861 & 36.7 & 3381 & 8.1 & 0.3 & 2.3 \\
2015 & 989 & 14.9 & 4370 & 8.4 & 0.3 & 2.3 \\
2016 & 1095 & 10.7 & 5465 & 8.6 & 0.2 & 3.5 \\
\hline
\end{tabular}

AGR: annual growth rate; RGR: relative growth rate; DT: doubling time 
Table 4 Average author per documents and author productivity per year (2006-2016)

\begin{tabular}{lllll}
\hline Year & Frequency & $\begin{array}{l}\% \\
N=5465\end{array}$ & $\begin{array}{l}\text { Total number } \\
\text { of authors }\end{array}$ & $\begin{array}{l}\text { Average number of } \\
\text { authors per document }\end{array}$ \\
\hline 2006 & 155 & 2.8 & 515 & 3.3 \\
2007 & 176 & 3.2 & 696 & 4.0 \\
2008 & 189 & 3.5 & 702 & 3.7 \\
2009 & 234 & 4.3 & 820 & 3.5 \\
2010 & 288 & 5.3 & 1092 & 3.8 \\
2011 & 343 & 6.3 & 1352 & 3.9 \\
2012 & 505 & 9.2 & 2165 & 4.3 \\
2013 & 630 & 11.5 & 2739 & 4.3 \\
2014 & 861 & 15.8 & 3943 & 4.6 \\
2015 & 989 & 18.1 & 3962 & 4.0 \\
2016 & 1095 & 20.0 & 5568 & 5.1 \\
Total & 5465 & 100 & 23554 & 4.0 \\
\hline
\end{tabular}

of time required for the number of publications to double in number in 1 year and was calculated based on the following equation: $D T=0.693 / R G R[19,34,35]$. Finally, the citation analysis was presented as total citations, mean and median (Q1 - Q3) citations. The quality of publications was measured using Hirsch index (h-index) and was obtained directly from Scopus.

\section{Collaboration and authorship analysis}

Author details were exported from Scopus to Microsoft Excel where authorship analysis was carried out. Analysis in Microsoft Excel included number of singleauthored articles and number of multi-authored (joint) articles. Analysis of overall collaboration in the field of
$\mathrm{m}$-Health was calculated using the following equation: Degree of collaboration $=C=N_{m} / N_{m}+N_{s}[19,34,35]$ where $\mathrm{N}_{\mathrm{m}}=$ number of multi-authored papers and $\mathrm{N}_{\mathrm{s}}=$ number of single-authored papers. The collaboration index $(\mathrm{CI})$ was calculated based on the number of multiauthored (joint) papers and the number of authors of these multi-authored (joint) papers. The equation used to calculate the collaboration index was as follows: $\mathrm{CI}=$ number of authors in joint articles/number of joint papers $[19,34,35]$. Authorship analysis included analysis of average number of authors per paper which was calculated as: $($ AAPP $)=$ total number of authors/total number of papers.

\section{Visualization and mapping}

Retrieved data were visualized using VOSviewer program, a software tool used for visualization of bibliometric networks. In visualization techniques, maps could be presented as a density map or as a network visualization in which color, circle size, font size, and thickness of connecting lines were used to present certain parameters. For example, units with similar color indicated that these units belonged to one cluster or group of close units that could be countries or authors. The strength of collaboration between countries was measured by the thickness of connecting lines which was numerically represented as relative link strength. Higher relative link strength suggested stronger collaboration. The larger circle size or font size indicated greater productivity or citations [36]. For geographical distribution of publications ArcGIS 10.1 (ArcMap 10.1), a geographic information system(GIS), was used. To create the geographical distribution map, retrieved data were exported to excel and then were transferred to ArcGIS 10.1 program to create the GIS map.

Table 5 Collaboration index (Cl) among authors in m-Health field (2006-2016)

\begin{tabular}{llllllllll}
\hline Year & Frequency & $\begin{array}{l}\text { \% } \\
N=5465\end{array}$ & $\begin{array}{l}\text { Total number } \\
\text { of authors }\end{array}$ & $\begin{array}{l}\text { Number of single } \\
\text { authored publications }\end{array}$ & $\begin{array}{l}\text { Number of multi- } \\
\text { authored publications }\end{array}$ & $\begin{array}{l}\text { number of authors in multi- } \\
\text { authored publications }\end{array}$ \\
\hline 2006 & 155 & 2.8 & 515 & 48 & 31.0 & 107 & 69.0 & 408 & 3.8 \\
2007 & 176 & 3.2 & 696 & 36 & 20.5 & 140 & 79.5 & 556 & 4.0 \\
2008 & 189 & 3.5 & 702 & 43 & 22.8 & 146 & 77.2 & 556 & 3.8 \\
2009 & 234 & 4.3 & 820 & 65 & 27.8 & 169 & 72.2 & 651 & 3.9 \\
2010 & 288 & 5.3 & 1092 & 59 & 20.5 & 229 & 79.5 & 863 & 3.8 \\
2011 & 343 & 6.3 & 1352 & 76 & 22.2 & 267 & 77.8 & 1085 & 4.1 \\
2012 & 505 & 9.2 & 2165 & 87 & 17.2 & 418 & 82.8 & 1747 & 4.2 \\
2013 & 630 & 11.5 & 2739 & 95 & 15.1 & 535 & 84.9 & 2204 & 4.1 \\
2014 & 861 & 15.8 & 3943 & 106 & 12.3 & 755 & 87.7 & 3188 & 4.2 \\
2015 & 989 & 18.1 & 3962 & 117 & 11.8 & 872 & 88.2 & 3090 \\
2016 & 1095 & 20.0 & 5568 & 95 & 8.7 & 1000 & 91.3 & 4568 \\
Total & 5465 & 100 & 23554 & 827 & 15.1 & 4638 & 84.9 & 18916 \\
\hline
\end{tabular}

Cl: Collaboration index 
Rodrigues].J.P.C.

KimH.-S.

Meyer C.

Haug S.

Cafazzo J.A.

Tarassenkol. SchûzJ. Piette J.D.

Bakken S.

Ben-Zeev D. Redfern J.

Whittaker R.

Freec.

Lee $S$.

Kumar S.

Car J.

LiuY.

Aroras.

@ VOSviewer

Fig. 2 Network visualization map of active authors in m-Health. Authors with a minimum of 10 publications and 100 citations were visualized. The map included 30 authors who met the criteria of being an active author. Some names might not be seen due to overlap of names. Closed circles indicated active authors of close research collaboration

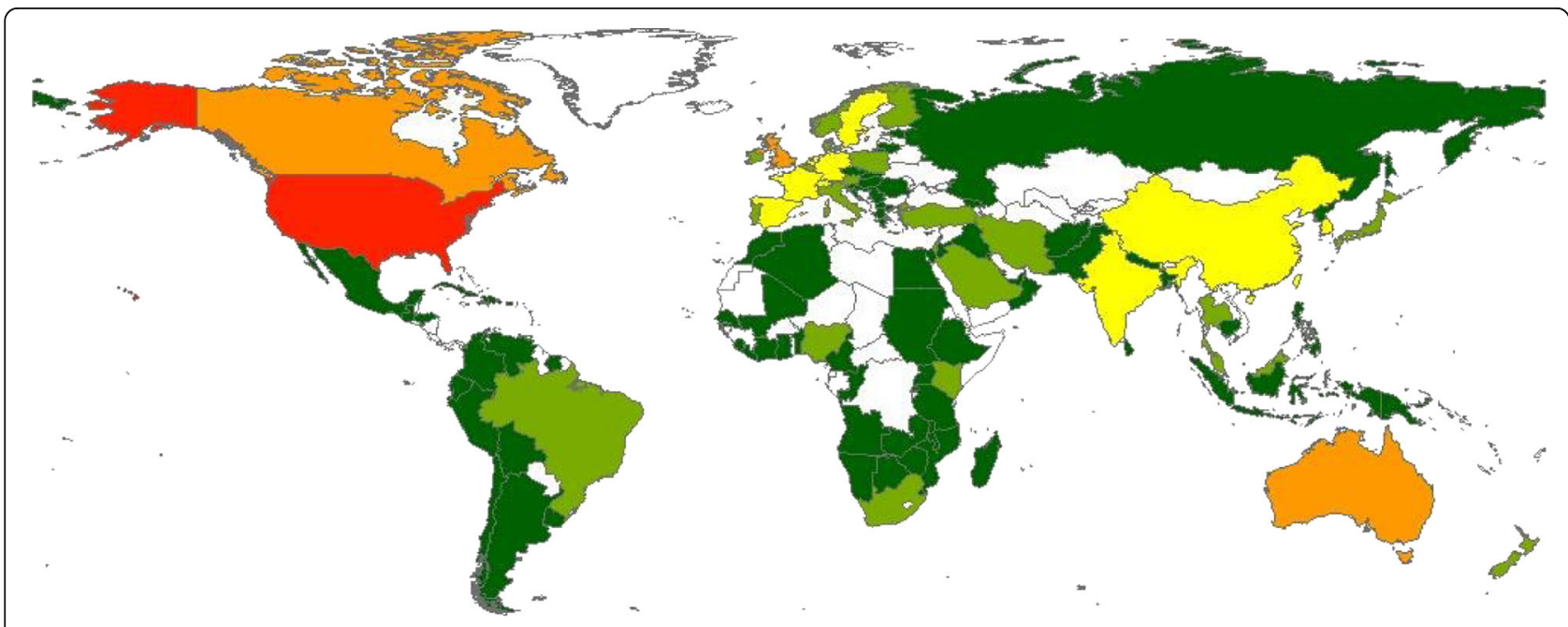

Number of articles

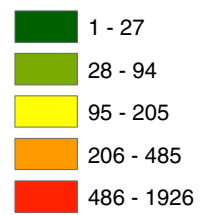

Fig. 3 Geographical distribution of publication in m-Health. The map was created using ArcGIS 10.1 software. The map is color coded where world regions with red color had the highest productivity while world regions with dark green had the lowest productivity. Areas with no color indicates no data available from these areas 


\section{Statistical analysis and ethics}

Descriptive statistics for categorical variables such as frequencies and percentages were presented. For continuous data, mean, median, and range were represented. For median, the interquartile range (Q1-Q3) was presented. No statistical testing was carried out. For data analysis and presentation, Microsoft Excel and Statistical Package for Social Sciences (SPSS 20) were used. Graphics was made using SPSS 20. This study included no human subjects and is based on electronic data and therefore it was exempted from ethical approval.

\section{Results}

\section{Description of retrieved literature}

A total of 5465 documents were retrieved; the majority (4194; 76.7\%) were research articles. The second most common type of document was review articles which constituted 9.6\%. Details about types of retrieved documents were shown in Table 1 . The majority of retrieved documents were published in English (5118; 93.7\%). Other commonly encountered languages included French (130; 2.4\%) and German (72, 1.3\%). Retrieved documents received a total of 54937 citations, a mean of $10.8 \pm 31$ citations per document; median (Q1-Q3) of $2(0-10)$, and a range of 449 (0-449). The $h$-index of retrieved documents was 81. Mapping with VOSviewer technique of author keywords with minimum occurrences of 25 showed that keywords such as type 2 diabetes/diabetes mellitus; HIV, medication adherence, obesity, weight loss, physical activity, mental health, hypertension, health promotion, smoking cessation, addiction, depression, and self-management were most encountered author keywords after exclusion of the core keywords related to search query (Fig. 1).

\section{Growth of publications}

The mean number of publications during the study period was 496.8 documents per year. The highest productivity was observed in 2016 with a total of 1095 (20.0\%) documents and the lowest productivity was in 2006 with a total productivity of 155 (2.8\%). There was an increase in the number of publications during the study period. The total number of citations per year for retrieved documents is shown in Table 2. The number of citations per document was highest for documents published in 2009 (21.2 citations per document) while the lowest was for those published in 2016 (0.8 citations per document) due to short time elapsed since publications. Growth analysis indicated that AGR had a fluctuating pattern during the study period (Table 3 ). RGR declined from 0.8 in 2007 to 0.3 in 2009 and then remained stable at 0.3 from 2009 to 2015 followed by a decline to 0.2 in 2016. The DT increased from 0.9 in 2007 to 2.3 in 2009 and continued to remain at 2.3 until 2015 followed by an increase in 2016 to 3.5. Stable values of RGR and DT indicated exponential growth of publications.

\section{Authorship pattern, collaboration, and prolific authors}

A total number of 23554 researchers participated in publishing retrieved documents giving a mean of $4.0 \mathrm{au}-$ thors per document. The mean number of authors per document showed an increasing trend with time; from 3.3 in 2006 to 5.1 in 20016 (Table 4). A total of 827 (15.1\%) documents were single-authored publications while the remaining documents $(4638 ; 84.9 \%)$ were multi-authored publications. Therefore, prevalence of team research or the degree of research collaboration among researchers in $\mathrm{m}$-Health was $84.9 \%$. The collaboration index (CI) for multi-authored documents increased from 3.8 in 2006 to 4.6 in 2016; with a mean of 4.1 authors per document in multi-authored (joint) publications (Table 5). Authors with a minimum productivity of 10 documents and a minimum total citation of 100 were visualized using VOSviewer technique and presented in Fig. 2. The map included 30 circles, each representing one author. Closer circles indicate authors with close research collaboration.

Table 6 Countries with a minimum productivity of 50 documents in the field of mobile health

\begin{tabular}{|c|c|c|c|}
\hline Rank & Country & Frequency & $\begin{array}{l}\% \\
N=5465\end{array}$ \\
\hline 1 & United States & 1926 & 35.2 \\
\hline 2 & United Kingdom & 485 & 8.9 \\
\hline 3 & Australia & 280 & 5.1 \\
\hline 4 & Canada & 268 & 4.9 \\
\hline 5 & South Korea & 205 & 3.8 \\
\hline 6 & India & 183 & 3.3 \\
\hline 7 & Germany & 173 & 3.2 \\
\hline 8 & China & 155 & 2.8 \\
\hline 9 & Spain & 153 & 2.8 \\
\hline 10 & France & 149 & 2.7 \\
\hline 11 & Netherlands & 116 & 2.1 \\
\hline 12 & Sweden & 113 & 2.1 \\
\hline 13 & Switzerland & 106 & 1.9 \\
\hline 14 & Italy & 94 & 1.7 \\
\hline 15 & South Africa & 80 & 1.5 \\
\hline 16 & Japan & 72 & 1.3 \\
\hline 16 & Taiwan & 72 & 1.3 \\
\hline 18 & New Zealand & 65 & 1.2 \\
\hline 19 & Turkey & 60 & 1.1 \\
\hline 20 & Denmark & 55 & 1.0 \\
\hline 21 & Iran & 54 & 1.0 \\
\hline 22 & Norway & 50 & 0.9 \\
\hline
\end{tabular}




\section{Geographical distribution of publications}

Researchers from 120 different countries contributed to the publication of retrieved documents. The distribution of publications on world map using ArcMap 10.1 software was shown in Fig. 3. Countries with a minimum productivity of 50 publications are listed in Table 6 . The United States of America (USA) ranked first with a total of 1926 (35.2\%) documents followed by the United Kingdom (UK) and Australia.

Visualization of collaboration among countries with minimum productivity of 50 documents was shown in Fig. 4. The map showed 22 countries distributed in four different clusters; each with a different color. The strongest collaboration was among the following pairs of countries: USA-UK (link strength $=71$ ); USA-Canada (link strength $=62$ ); USA-India (link strength $=28$ ); USA-South Africa (link strength $=36$ ); USA-China (link strength = 33); UK-Australia (link strength $=28$ ).

Institutions/organizations involved in $\mathrm{m}$-health publications and had a minimum of 30 publications in the field were presented in Table 7. Most active institutions/ organizations in the field were in the USA. VA Medical Center in USA was the most productive institution/ organization in publishing articles in $\mathrm{m}$-Health and ranked first with a total of 85 documents.

\section{Preferred journals}

Journals with a minimum productivity of 20 documents were listed in Table 8. Journal of Medical Internet
Research ranked first with 193 (3.5\%) documents. Figure 5 is a network visualization map for co-citation analysis for journals with minimum citations of 300. Journal of Medical Internet Research received the highest number of connecting lines from other journals indicating that this journal was being co-cited with most other journals. Furthermore, the Journal of Medical Internet Research had the largest circle size indicative of having the highest number of citations in m-Health.

\section{Top cited documents}

Top 10 cited articles in the field of $\mathrm{m}$-Health were shown in Table 9. The top cited documents included seven research articles, two review articles and one editorial. The article that received the highest citation, "Effects of a mobile phone short message service on antiretroviral treatment adherence in Kenya (WelTel Kenya1): A randomised trial", was published in Lancet in 2010 and received a total of 449 citations. The top to cited articles included two articles about antiretroviral medication adherence, one article about diabetes mellitus, one article about weight loss, one article about health behavior and the others were general articles on mobile-health. The top cited articles were published in journals in the field of internet or in general medicine.

\section{Discussion}

In this study, bibliometric indicators of literature in mHealth were sought. English language remained the

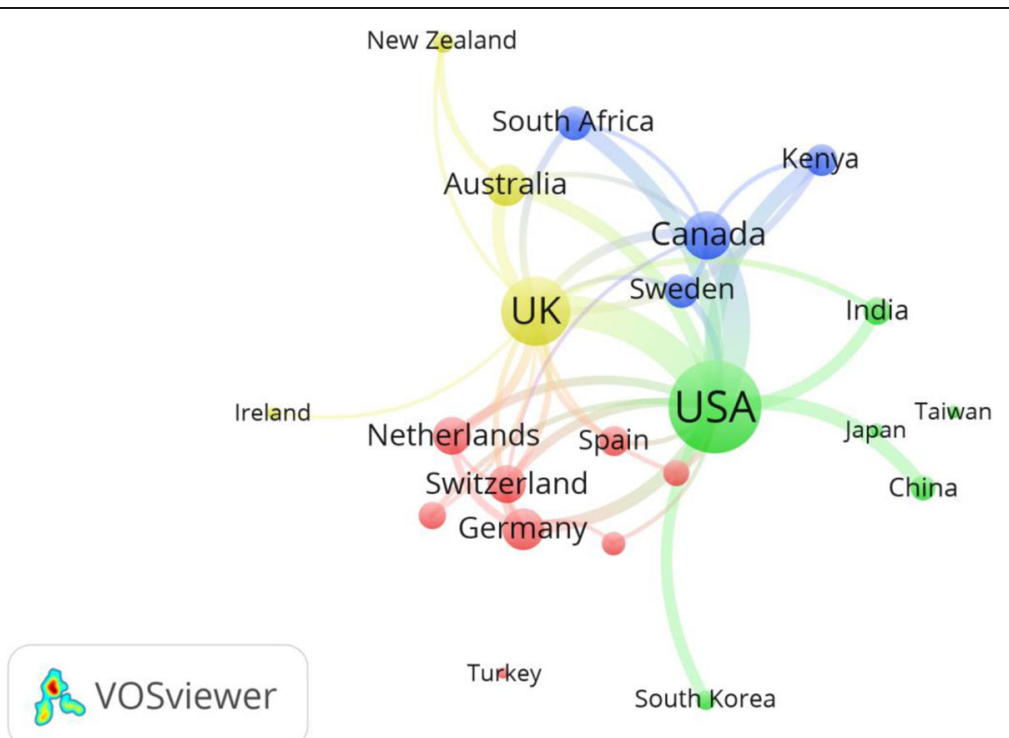

Fig. 4 Network visualization map of international collaboration among countries with a minimum productivity of 50 documents. The thickness of connecting line between any two countries indicates strength of collaboration. For example, the link strength (collaboration) between USA and UK was 71 and it represents a thick line. On the other hand, the line between USA and India had a link strength of 28. Countries with similar color form one cluster. For example, countries with red color such as Germany and Netherlands existed in one cluster and had the highest percentage of collaboration within this cluster. India, Japan, Taiwan, and South Korea were clustered in green since the bulk of their collaboration is with the USA, so they are grouped with USA 
Table 7 Institutions and organizations with a minimum productivity of 30 documents in m-Health (2006-2016)

\begin{tabular}{|c|c|c|c|c|}
\hline Rank & Institution/Organization & Frequency & $\%(N=5465)$ & Country \\
\hline 1 & VA Medical Center & 85 & 1.6 & USA \\
\hline 2 & University of Washington, Seattle & 64 & 1.2 & USA \\
\hline 3 & The University of Sydney & 60 & 1.1 & Australia \\
\hline 4 & University of California, San Francisco & 59 & 1.1 & USA \\
\hline 5 & Karolinska Institutet & 57 & 1.0 & Sweden \\
\hline 6 & The University of British Columbia & 54 & 1.0 & Canada \\
\hline 7 & Massachusetts General Hospital & 52 & 1.0 & USA \\
\hline 8 & London School of Hygiene \& Tropical Medicine & 49 & 0.9 & UK \\
\hline 9 & Harvard Medical School & 48 & 0.9 & USA \\
\hline 9 & University of Pittsburgh & 48 & 0.9 & USA \\
\hline 9 & University of Toronto & 48 & 0.9 & Canada \\
\hline 9 & Columbia University in the City of New York & 48 & 0.9 & USA \\
\hline 13 & Imperial College London & 44 & 0.8 & UK \\
\hline 14 & Johns Hopkins Bloomberg School of Public Health & 43 & 0.8 & USA \\
\hline 15 & University of California, Los Angeles & 41 & 0.8 & USA \\
\hline 16 & University Michigan Ann Arbor & 38 & 0.7 & USA \\
\hline 16 & University of Oxford & 38 & 0.7 & UK \\
\hline 18 & Duke University & 36 & 0.7 & USA \\
\hline 19 & University of Auckland & 34 & 0.6 & New Zealand \\
\hline 19 & University of New South Wales UNSW Australia & 34 & 0.6 & Australia \\
\hline 21 & Johns Hopkins University & 33 & 0.6 & USA \\
\hline 21 & The University of North Carolina at Chapel Hill & 33 & 0.6 & USA \\
\hline 23 & David Geffen School of Medicine at UCLA & 31 & 0.6 & USA \\
\hline 23 & Northwestern University Feinberg School of Medicine & 31 & 0.6 & USA \\
\hline 23 & University Health Network University of Toronto & 31 & 0.6 & Canada \\
\hline 23 & UCL (University College London) & 31 & 0.6 & UK \\
\hline 23 & University of Queensland & 31 & 0.6 & Australia \\
\hline 28 & Brigham and Women's Hospital & 30 & 0.5 & USA \\
\hline
\end{tabular}

language of science in m-Health field with more than 93\% of retrieved documents were written in English. Literature in $\mathrm{m}$-Health were dominated by multi-authored publications. Data presented in our study indicated that pattern of authorship showed an increasing pattern of number of authors per document with time. Compared with other disciplines, the prevalence of multi-authored publications and collaboration index presented in our study were higher than that in the field of zoology [37], marine science [38], and information technology [35]. This might be due to the nature of the m-Health field which included two disciplines, medicine and technology, and therefore might require authors from different disciplines. Furthermore, the availability of diverse means of communication among researchers in different world regions made team research and collaboration easier and more practical which reflected positively on the prevalence of multiauthored publications seen in our study.
The USA ranked first in productivity, but contribution by European and Asian countries was also prominent. Literature in $\mathrm{m}$-Health covered a wide range of health aspects including diabetes mellitus, medication adherence to anti-HIV medications, and several other aspects related to cardiovascular and chronic diseases. The Journal of Medical Internet Research was the most preferred journal for publishing documents in $\mathrm{m}$-Health. The VA Medical Center in USA was the most productive institution. The volume of literature in $\mathrm{m}$-health showed an exponential increase in the second half of the study, i.e., after 2009. Along with the increase in volume literature, there was an increasing trend of mean number of authors per document with time indicative of an increase in research collaboration among authors.

Mobile health applications had witnessed rapid spread in developed countries were technology and prosperous economy helped in developing healthcare services through 
Table 8 Journal names with minimum productivity of 20 publications in m-Health (2006-2016)

\begin{tabular}{|c|c|c|c|}
\hline Rank & Journal & Frequency & $\begin{array}{l}\% \\
N=5465\end{array}$ \\
\hline 1 & Journal of Medical Internet Research & 193 & 3.5 \\
\hline 2 & Telemedicine and E Health & 129 & 2.4 \\
\hline 3 & Plos One & 77 & 1.4 \\
\hline 4 & Journal of Telemedicine and Telecare & 67 & 1.2 \\
\hline 5 & Telemedicine Journal and E Health & 52 & 1.0 \\
\hline 6 & Journal of Medical Systems & 50 & 0.9 \\
\hline 7 & BMC Public Health & 48 & 0.9 \\
\hline 8 & $\begin{array}{l}\text { Annual International Conference of the IEEE } \\
\text { Engineering in Medicine and Biology Society }\end{array}$ & 46 & 0.8 \\
\hline 9 & $\begin{array}{l}\text { BMC Medical Informatics And Decision } \\
\text { Making }\end{array}$ & 40 & 0.7 \\
\hline 9 & International Journal of Medical Informatics & 40 & 0.7 \\
\hline 11 & Journal of Diabetes Science and Technology & 38 & 0.7 \\
\hline 12 & Health Informatics Journal & 28 & 0.5 \\
\hline 13 & AIDS and Behavior & 27 & 0.5 \\
\hline 13 & Trials & 27 & 0.5 \\
\hline 15 & Journal of Health Communication & 26 & 0.5 \\
\hline 16 & BMJ Open & 25 & 0.5 \\
\hline 16 & Diabetes Technology and Therapeutics & 25 & 0.5 \\
\hline 18 & AMIA Annual Symposium Proceedings & 24 & 0.4 \\
\hline 19 & $\begin{array}{l}\text { Journal of the American Medical Informatics } \\
\text { Association }\end{array}$ & 23 & 0.4 \\
\hline 20 & Journal of the Royal Army Medical Corps & 21 & 0.4 \\
\hline 20 & Sensors Switzerland & 21 & 0.4 \\
\hline 22 & Lancet & 20 & 0.4 \\
\hline 22 & Soins Gerontologie & 20 & 0.4 \\
\hline
\end{tabular}

most-up-to date technology. The advancement in technology and introduction of health application through smartphones and other mobile technologies will increase the access of people to health services and might decrease the burden on healthcare providers. For example, the new mobile health technologies allow individuals to monitor their blood pressure and heart rate and store these health data for future use. Patients with chronic diseases such as diabetes mellitus, hypertension, hemodialysis patients can use smartphones as medical records to store data regarding their diet, physical activity, life style changes, and even their day to day health changes and symptoms and present the data to healthcare providers when needed. This will help improve health system services especially in low and middle income countries where automated health system services are not well developed and numbers of healthcare providers might be limited. The power of technology in advancing health services should encourage governments, organizations, and individuals to invest in technology for better future health services. Actually, most of the emerging telecommunication technologies will be implemented directly or indirectly to health. Examples of new technologies include next-generation robotics and body-adapted wearable electronics.

The use of $\mathrm{m}$-Heath in low and middle income countries might help overcome the burden of diseases and poor health services in these countries [39-41]. A systematic review study on the impact of $\mathrm{m}$-Health intervention on outcome of chronic diseases reported a positive impact on chronic diseases in low and middle income countries [6]. No doubt that limited health services in many developing countries and the fast-growing mobile technology and its penetration into many low and middle income countries made the shift to $\mathrm{m}$ -

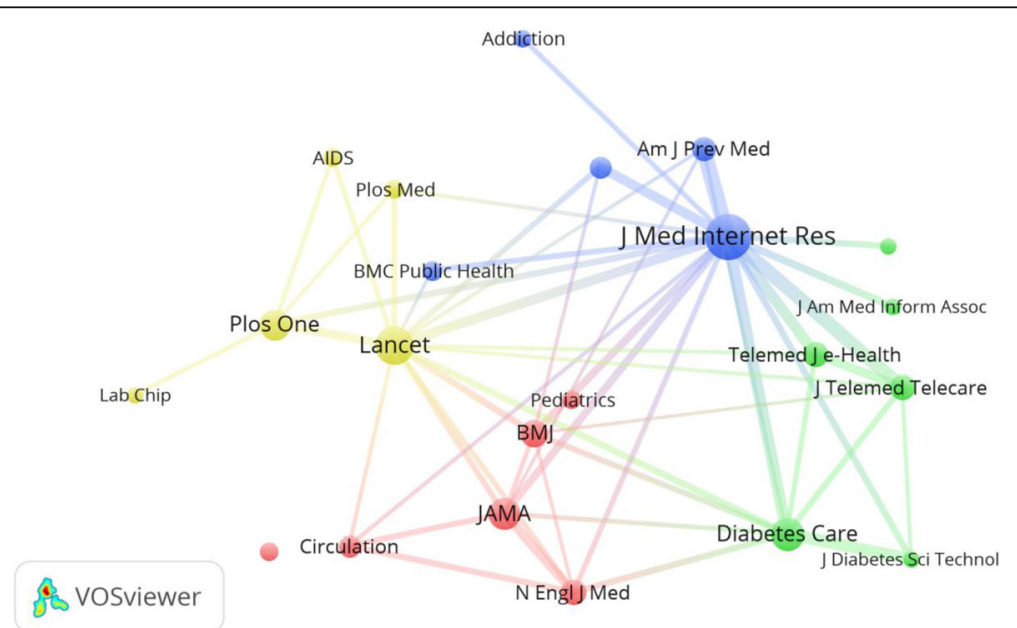

Fig. 5 Network visualization map of journal co-citation analysis for journals which published documents in m-Health with a minimum total of 300 citations. Journal of Medical Internet Research had many connecting lines with various journals indicating that this journal is being co-cited with various journals. Journals in the same cluster with the same color are being commonly co-cited together 
Table 9 Top 10 cited articles in m-Health literature (2006-2016)

\begin{tabular}{|c|c|c|c|c|c|c|}
\hline Rank & Title & Year & Journal name & Cited by & Reference & Type of document \\
\hline 1 & $\begin{array}{l}\text { "Effects of a mobile phone short message service } \\
\text { on antiretroviral treatment adherence in Kenya } \\
\text { (WelTel Kenya1): A randomised trial" }\end{array}$ & 2010 & The Lancet & 449 & [49] & Article \\
\hline 2 & $\begin{array}{l}\text { "Text messaging as a tool for behavior change in } \\
\text { disease prevention } \\
\text { and management" }\end{array}$ & 2010 & Epidemiologic Reviews & 419 & [12] & Review \\
\hline 3 & "Healthcare via cell phones: A systematic review" & 2009 & Telemedicine and e-Health & 386 & [18] & Article \\
\hline 4 & $\begin{array}{l}\text { "Mobile phone technologies improve adherence } \\
\text { to antiretroviral treatment in a resource-limited } \\
\text { setting: A randomized controlled trial of text } \\
\text { message reminders" }\end{array}$ & 2011 & AIDS & 352 & [59] & Article \\
\hline 5 & $\begin{array}{l}\text { "CONSORT-EHEALTH: improving and standardizing } \\
\text { evaluation reports of Web-based and mobile health } \\
\text { interventions." }\end{array}$ & 2011 & Journal of medical Internet research & 308 & [60] & Editorial \\
\hline 6 & $\begin{array}{l}\text { "How smartphones are changing the face of mobile } \\
\text { and participatory healthcare: An overview, with } \\
\text { example from eCAALYX" }\end{array}$ & 2011 & BioMedical Engineering Online & 299 & [61] & Review \\
\hline 7 & $\begin{array}{l}\text { "A randomized controlled trial of Sweet Talk, a } \\
\text { text-messaging system to support young people } \\
\text { with diabetes" }\end{array}$ & 2006 & Diabetic Medicine & 298 & [62] & Article \\
\hline 8 & $\begin{array}{l}\text { "Ecological momentary interventions: Incorporating } \\
\text { mobile technology } \\
\text { into psychosocial and health behaviour treatments" }\end{array}$ & 2010 & British Journal of Health Psychology & 293 & [7] & Article \\
\hline 9 & $\begin{array}{l}\text { "A text message-based intervention for weight loss: } \\
\text { Randomized controlled trial" }\end{array}$ & 2009 & Journal of Medical Internet Research & 278 & [63] & Article \\
\hline 10 & $\begin{array}{l}\text { "Mobile phone based clinical microscopy for global } \\
\text { health applications" }\end{array}$ & 2009 & PLOS ONE & 276 & {$[64]$} & Article \\
\hline
\end{tabular}

Health in these countries to be faster than expected. An interesting example of the power of $\mathrm{m}$-Health to advance health services and to reverse spread of diseases is a project called Masiluleke in South Africa which is a project that utilizes the power of communication through mobile devices to fight HIV/AIDS and tuberculosis which are major threatening public health issues for South Africa and Africa in general. The project brings powerful technology companies with nongovernmental organization and the government to promote health through technology. It was not surprising that Journal of AIDS and Behavior was among top preferred journals for publishing documents in $\mathrm{m}$-Health because technology have been invested to enhance awareness and prevention regarding AIDS. Documents published in AIDS journals focused mainly on improving adherence, risky sexual behavior, and health care for patients with AIDS $[42,43]$. It was not surprising also that some of the top cited articles in the field of $\mathrm{m}$-Health were in the field of medication adherence in HIV patients. Adherence to HIV medication is an important issue in medication adherence field in general and in AIDS patients in particular. A study reported that 95\% or greater adherence is needed to optimize virologic outcome for patients with HIV infection [44]. Poor adherence to anti-HIV therapies is believed to be the reason for less than one third of HIV patients in developed countries with adequate viral suppression [45]. Furthermore, the importance of medication adherence in HIV patients is related to avoidance of emergence of resistance to current anti-HIV therapies [46]. The use of m-Health to optimize anti-HIV medication adherence have been notice in several African countries where healthcare services are poor and HIV is widespread [26, 42, 47-49]. Implementation of m-Health had also been applied to non-communicable diseases such as diabetes mellitus and had shown to help patients manage their glycemic control [50-52].

Our study had few limitations that are inherent to the database used and to search query developed by the authors. Such limitations were encountered in previously published bibliometric studies [53-58]. It should be emphasized that despite the fact that Scopus is one of the largest databases, there are still unindexed journals and therefore publications in these un-indexed journals might have been missed. Furthermore, no search query is $100 \%$ perfect and false positive and false negative results are always a possibility. The ranking of authors and institutions presented in our study was based on data presented by Scopus. However, in certain cases, some authors or institutions might have more than one name or different name spelling. This might create an inaccuracy in the productivity of these 
institutions or authors. Despite all these limitations, our study was the first to analyze bibliometric indicators of $\mathrm{m}$ Health literature. Previously published bibliometric studies in the field of mobile technology [34] endorsed the findings of our study regarding growth and authorship pattern.

\section{Conclusion}

Mobile health is an emerging and promising field that is expected to change several aspects of health services in both communicable and non-communicable diseases. Investing in $\mathrm{m}$-Health should be a priority for governments, organizations and even individual patients. The emerging new mobile technologies should be tailored to help people and countries to improve national health and face major public health crisis. The data presented here will also serve for comparative future purposes to document the impact of $\mathrm{m}$-Health on future research.

\section{Additional file}

Additional file 1: Appendix 1a. List of functions available in Scopus
that allows for refining of data based on various parameters. Appendix 1b.
Source types of retrieved documents. In the current study, only journal
publications were selected and analyzed. Appendix 1c. Types of
documents showed up when retrieved data are limited to journal
publications. Appendix 1d. Search strategy using the term "mobile health"
in title-abstract-keyword. Appendix 1e. Search strategy using title search for
words pertaining to mobile technology and health terms. Appendix 1f.
Overall search strategy to retrieve documents in m-Health (2006-2016).
Search strategy for literature in m-Health. The appendix consist of six
illustrations that explain the steps and strategy implemented in
Scopus database to retrieve literature in m-Health. (DOCX $599 \mathrm{~kb})$

\section{Acknowledgements}

The authors would like to thank An-Najah National University and WHO's Health Inter Network Access to Research Initiative (HINARI) for giving us the opportunities to access most recent information sources such as Scopus database.

\section{Funding}

No funding was received for writing this study.

\section{Availability of data and materials}

Data can be retrieved from Scopus using search query presented in methodology.

\section{Authors' contributions}

W.S. led the study design, data collection, statistical analysis, and drafting of the manuscript, SA, S.Z., A.A., A.S. F.A. participated in the study design, and revised the article for important intellectual content. All authors read and approved the final manuscript and agreed on its submission.

\section{Competing interests}

The author declares that he has no competing interests.

\section{Consent for publication}

Not applicable.

\section{Ethics approval and consent to participate}

As a bibliometric study, no patients were involved in this type of analysis. Therefore, there was no need for Institutional Review Board approval and it was exempted based upon the design of this study.

\section{Publisher's Note}

Springer Nature remains neutral with regard to jurisdictional claims in published maps and institutional affiliations.

\section{Author details}

'Department of Physiology, Pharmacology and Toxicology, College of Medicine and Health Sciences, An-Najah National University, Nablus, Palestine. ${ }^{2}$ Department of Clinical and Community Pharmacy, College of Medicine and Health Sciences, An-Najah National University, Nablus, Palestine. ${ }^{3}$ College of Engineering and Technology, Palestine Technical University-Kadoorie (PTUK), Technical University - Kadoorie, P.O. Box 7Yafa Street, Tulkarm, Palestine.

Received: 17 January 2017 Accepted: 23 May 2017

Published online: 30 May 2017

\section{References}

1. Istepanian RS, Lacal JC. Emerging mobile communication technologies for health: some imperative notes on m-health, Engineering in Medicine and Biology Society, 2003 Proceedings of the 25th Annual International Conference of the IEEE: 2003: IEEE. 2003. p. 1414-6.

2. Silva BM, Rodrigues JJ, de la Torre DI, López-Coronado M, Saleem K. Mobilehealth: a review of current state in 2015. J Biomed Inform. 2015;56:265-72.

3. Cipresso P, Serino S, Villani D, Repetto C, Sellitti L, Albani G, Mauro A, Gaggioli A, Riva G. Is your phone so smart to affect your state? An exploratory study based on psychophysiological measures. Neurocomputing. 2012;84:23-30.

4. Adibi S: Mobile health: a technology road map, Springer: vol. 5. 2015.

5. Della Mea V. What is e-health (2): the death of telemedicine? J Med Internet Res. 2001;3(2):e22.

6. Beratarrechea A, Lee AG, Willner JM, Jahangir E, Ciapponi A, Rubinstein A. The impact of mobile health interventions on chronic disease outcomes in developing countries: a systematic review. Telemed J E Health. 2014;20(1): 75-82.

7. Heron KE, Smyth JM. Ecological momentary interventions: Incorporating mobile technology into psychosocial and health behaviour treatments. $\mathrm{Br}$ J Health Psychol. 2010;15(1):1-39.

8. de Jongh T, Gurol-Urganci I, Vodopivec-Jamsek V, Car J, Atun R. Mobile phone messaging for facilitating self-management of long-term illnesses. Cochrane Database Syst Rev. 2012:2012:12.

9. Quinn CC, Shardell MD, Terrin ML, Barr EA, Ballew SH, Gruber-Baldini AL. Cluster-randomized trial of a mobile phone personalized behavioral intervention for blood glucose control. Diabetes Care. 2011;34(9):1934-42.

10. Wang $Y$, Xue H, Huang $Y$, Huang L, Zhang D. A Systematic Review of Application and Effectiveness of mHealth Interventions for Obesity and Diabetes Treatment and Self-Management. Adv Nutr. 2017;8(3):449-62.

11. Liang X, Wang Q, Yang X, Cao J, Chen J, Mo X, Huang J, Wang L, Gu D. Effect of mobile phone intervention for diabetes on glycaemic control: $A$ meta-analysis. Diabet Med. 2011;28(4):455-63.

12. Cole-Lewis $H$, Kershaw T. Text messaging as a tool for behavior change in disease prevention and management. Epidemiol Rev. 2010;32(1):56-69.

13. Lim MSC, Hocking JS, Hellard ME, Aitken CK. SMS STI: A review of the uses of mobile phone text messaging in sexual health. Int J STD AIDS. 2008;19(5): 287-90.

14. Free $C$, Knight R, Robertson S, Whittaker R, Edwards P, Zhou W, Rodgers A, Cairns J, Kenward MG, Roberts I. Smoking cessation support delivered via mobile phone text messaging (txt2stop): A single-blind, randomised trial. Lancet. 2011;378(9785):49-55.

15. Lester RT, Ritvo P, Mills EJ, Kariri A, Karanja S, Chung MH, Jack W, Habyarimana J, Sadatsafavi M, Najafzadeh M, et al. Effects of a mobile phone short message service on antiretroviral treatment adherence in Kenya (WelTel Kenya1): A randomised trial. Lancet. 2010;376(9755):1838-45.

16. Luxton DD, McCann RA, Bush NE, Mishkind MC, Reger GM. MHealth for mental health: Integrating smartphone technology in behavioral healthcare. Prof Psychol Res Pract. 2011;42(6):505-12.

17. Haapala I, Barengo NC, Biggs S, Surakka L, Manninen P. Weight loss by mobile phone: A 1-year effectiveness study. Public Health Nutr. 2009;12(12):2382-91.

18. Krishna S, Boren SA, Balas EA. Healthcare via cell phones: A systematic review. Telemed e-Health. 2009;15(3):231-40.

19. Santhakumar R, Kaliyaperumal K. Mapping of mobile technology publications: A scientometric approach. DESIDOC J Library Inf Technol. 2014, 34(4). 
20. Kaliyaperumal K. A scientometric analysis of mobile technology publications. Scientometrics. 2015;105(2):921-39.

21. Aksnes DW, Rørstad K, Piro FN, Sivertsen G. Are mobile researchers more productive and cited than non-mobile researchers? A large-scale study of Norwegian scientists. Res Eval. 2013;22(4):215-23.

22. Fatehi F, Wootton R. Telemedicine, telehealth or e-health? A bibliometric analysis of the trends in the use of these terms. J Telemed Telecare. 2012; 18(8):460-4.

23. Groneberg DA, Rahimian S, Bundschuh M, Schwarzer M, Gerber A, Kloft B. Telemedicine - a scientometric and density equalizing analysis. J Occup Med Toxicol. 2015;10:38.

24. Falagas ME, Pitsouni El, Malietzis GA, Pappas G. Comparison of PubMed, Scopus, Web of Science, and Google Scholar: strengths and weaknesses. FASEB J. 2008;22(2):338-42.

25. Kumar S, Nilsen WJ, Abernethy A, Atienza A, Patrick K, Pavel M, Riley WT, Shar A, Spring B, Spruijt-Metz D, et al. Mobile health technology evaluation: The mHealth evidence workshop. Am J Prev Med. 2013;45(2):228-36.

26. Aranda-Jan CB, Mohutsiwa-Dibe N, Loukanova S. Systematic review on what works, what does not work and why of implementation of mobile health (mHealth) projects in Africa. BMC Public Health. 2014;14(1):188.

27. Silva BMC, Rodrigues JJPC, de la Torre DI, López-Coronado M, Saleem K. Mobile-health: A review of current state in 2015. J Biomed Inform. 2015;56: 265-72.

28. Källander K, Tibenderana JK, Akpogheneta OJ, Strachan DL, Hill Z, Asbroek AHAT, Conteh L, Kirkwood BR, Meek SR. Mobile health (mhealth) approaches and lessons for increased performance and retention of community health workers in lowand middle-income countries: A review. J Med Internet Res. 2013;15(1):e17.

29. Martínez-Pérez B, De La Torre-Díez I, López-Coronado M. Mobile health applications for the most prevalent conditions by the world health organization: Review and analysis. J Med Internet Res. 2013;15(6):e120.

30. Bastawrous A, Armstrong MJ. Mobile health use in low-and high-income countries: An overview of the peer-reviewed literature. J R Soc Med. 2013; 106(4):130-42.

31. Free C, Phillips G, Galli L, Watson L, Felix L, Edwards P, Patel V, Haines A. The Effectiveness of Mobile-Health Technology-Based Health Behaviour Change or Disease Management Interventions for Health Care Consumers: A Systematic Review. PLoS Med. 2013;10(1):e1001362.

32. Free C, Phillips G, Watson L, Galli L, Felix L, Edwards P, Patel V, Haines A. The Effectiveness of Mobile-Health Technologies to Improve Health Care Service Delivery Processes: A Systematic Review and Meta-Analysis. PLoS Med. 2013; 10(1):e1001363.

33. Steinhubl SR, Muse ED, Topol EJ. The emerging field of mobile health. Sci Transl Med. 2015;7(283):283rv3.

34. Santha Kumar R, Kaliyaperumal K. Scientometric Analysis of Global Publication Output in Mobile Technology. DESIDOC J Library Inf Technol. 2015;35(4):287-92.

35. Khaparde V, Pawar S. Authorship pattern and degree of collaboration in Information Technology. J Comput Sci Inf Technol. 2013;1(1):46-54.

36. van Eck NJ, Waltman L. VOSviewer manual, vol. 1. Leiden: Univeristeit Leiden; 2013.

37. Vimala V, Reddy VP. Authorship pattern and collaborative research in the field of zoology. Malays J Libr Inf Sci. 1996;1(2):43-50.

38. Elango B, Rajendran P. Authorship trends and collaboration pattern in the marine sciences literature: a scientometric study. Int J Inf Dissemination Technol. 2012;2(3):166.

39. Kahn JG, Yang JS, Kahn JS. Mobile'health needs and opportunities in developing countries. Health Aff. 2010;29(2):252-8.

40. Kaplan WA. Can the ubiquitous power of mobile phones be used to improve health outcomes in developing countries? Glob Health. 2006;2(1):1.

41. Déglise C, Suggs LS, Odermatt P. SMS for disease control in developing countries: a systematic review of mobile health applications. J Telemed Telecare. 2012;18(5):273-81.

42. Lim MS, Hocking JS, Hellard ME, Aitken CK. SMS STI: a review of the uses of mobile phone text messaging in sexual health. Int J STD AIDS. 2008;19(5): 287-90.

43. Haberer JE, Kiwanuka J, Nansera D, Wilson IB, Bangsberg DR. Challenges in using mobile phones for collection of antiretroviral therapy adherence data in a resource-limited setting. AIDS Behav. 2010;14(6):1294-301.

44. Paterson DL, Swindells S, Mohr J, Brester M, Vergis EN, Squier C, Wagener MM, Singh N, Hudson B. Adherence to protease inhibitor therapy and outcomes in patients with HIV infection. Ann Intern Med. 2000;133(1):21-30.
45. Control CfD, Prevention. Vital signs: HIV prevention through care and treatment-United States. MMWR Morb Mortal Wkly Rep. 2011;60(47):1618.

46. Harrigan PR, Hogg RS, Dong WW, Yip B, Wynhoven B, Woodward J, Brumme CJ, Brumme ZL, Mo T, Alexander CS, et al. Predictors of HIV drugresistance mutations in a large antiretroviral-naive cohort initiating triple antiretroviral therapy. J Infect Dis. 2005;191(3):339-47.

47. Chib A, Wilkin H, Ling LX, Hoefman B, Van Biejma H. You have an important message! Evaluating the effectiveness of a text message HIV/AIDS campaign in Northwest Uganda. J Health Commun. 2012;17(sup1):146-57.

48. Betjeman TJ, Soghoian SE, Foran MP. mHealth in Sub-Saharan Africa. Int J Telemed Appl. 2013:2013:482324.

49. Lester RT, Ritvo P, Mills EJ, Kariri A, Karanja S, Chung MH, Jack W, Habyarimana J, Sadatsafavi M, Najafzadeh M. Effects of a mobile phone short message service on antiretroviral treatment adherence in Kenya (WelTel Kenya1): a randomised trial. Lancet. 2010;376(9755):1838-45.

50. Mougiakakou SG, Kouris I, Iliopoulou D, Vazeou A, Koutsouris D. Mobile technology to empower people with Diabetes Mellitus: Design and development of a mobile application, 9th International Conference on Information Technology and Applications in Biomedicine: 2009: IEEE. 2009. p. 1-4.

51. Liang X, Wang Q, Yang X, Cao J, Chen J, Mo X, Huang J, Wang L, Gu D. Effect of mobile phone intervention for diabetes on glycaemic control: a meta-analysis. Diabet Med. 2011;28(4):455-63.

52. Kollmann A, Riedl M, Kastner P, Schreier G, Ludvik B. Feasibility of a mobile phone-based data service for functional insulin treatment of type 1 diabetes mellitus patients. J Med Internet Res. 2007;9(5):e36.

53. Sweileh WM. Global research trends of World Health Organization's top eight emerging pathogens. Global Health. 2017;13(1):9.

54. Sweileh WM. Bibliometric analysis of literature on toxic epidermal necrolysis and Stevens-Johnson syndrome: 1940-2015. Orphanet J Rare Dis. 2017;12(1):14.

55. Sweileh WM, AbuTaha AS, Sawalha AF, Al-Khalil S, Al-Jabi SW, Zyoud SH Bibliometric analysis of worldwide publications on multi-, extensively, and totally drug-resistant tuberculosis (2006-2015). Multidisciplinary Respir Med. 2016;11:45.

56. Sweileh WM, Al-Jabi SW, Sawalha AF, AbuTaha AS, Zyoud SH. Bibliometric analysis of publications on Campylobacter: (2000-2015). J Health Popul Nutr. 2016:35(1):39.

57. Sweileh WM, Sawalha AF, Al-Jabi SW, Zyoud SH, Shraim NY, Abu-Taha AS. A bibliometric analysis of literature on malaria vector resistance: (1996-2015). Glob Health. 2016;12(1):76

58. Sweileh WM, Shraim NY, Al-Jabi SW, Sawalha AF, AbuTaha AS, Zyoud SH. Bibliometric analysis of global scientific research on carbapenem resistance (1986-2015). Ann Clin Microbiol Antimicrob. 2016;15(1):56.

59. Kelly JD, Giordano TP. Mobile phone technologies improve adherence to antiretroviral treatment in a resource-limited setting: a randomized controlled trial of text message reminders. AIDS. 2011;25(8):1137.

60. Eysenbach G. CONSORT-EHEALTH: improving and standardizing evaluation reports of Web-based and mobile health interventions. J Med Internet Res. 2011;13(4):e126.

61. Boulos MNK, Wheeler S, Tavares C, Jones R. How smartphones are changing the face of mobile and participatory healthcare: an overview, with example from eCAALYX. Biomed Eng Online. 2011;10(1):1.

62. Franklin VL, Waller A, Pagliari C, Greene SA. A randomized controlled trial of Sweet Talk, a text-messaging system to support young people with diabetes. Diabet Med. 2006;23(12):1332-8.

63. Patrick K, Raab F, Adams M, Dillon L, Zabinski M, Rock C, Griswold W, Norman G. A text message-based intervention for weight loss: randomized controlled trial. J Med Internet Res. 2009;11(1):e1.

64. Breslauer DN, Maamari RN, Switz NA, Lam WA, Fletcher DA. Mobile phone based clinical microscopy for global health applications. PLoS One. 2009; 4(7):e6320. 